\title{
Evidence-based and precision medicine two of a kind
}

In the last two decades, an enormous expansion of evidence has been produced in upper airway research.

When writing the first EPOS document in 2005, only 5 RCT per year were performed in the area of CRS, in 2007 this changed to 25 per year and it became even higher in the recent years ${ }^{(1-3)}$. Randomized Controlled Trials (RCTs) are the "gold standard" for evaluating treatment outcomes providing information on treatments "efficacy". To make life easier for clinicians, systematic reviews and meta-analysis further condense the available evidence ${ }^{(4-6)}$.

In Rhinology, in the last few years, a number of systematic reviews ${ }^{(7-10)}$, meta-analyses ${ }^{(11,12)}$ and RCT's ${ }^{(13-17)}$ have been published to help clinicians to guide their practice. This evidence has brought us a lot of good: we now know that it is not useful to treat simple acute rhinosinusitis patients with antibiotics (7), and that intra-operative use of local and systemic tranexamic acid in ESS, results in significantly reduced estimated blood loss and improved surgical field quality, but no statistically significant difference in operative time or incidence of side effects ${ }^{(10)}$. In this issue, we have two very interesting systematic reviews: one on the effect of olfactory training ${ }^{(12)}$. The group of Prof. Hummel shows that there is a significant, positive effect of olfactory training for all olfactory abilities, with large effects of training on identification, discrimination and TDI-score and small-to-moderate effect in the case of threshold for odour detection. Although the exact mechanism of olfactory recovery following the smell training still requires further investigation, this meta-analysis shows that such training should be have a place in daily clinical practice. The other systematic review and meta-analysis concluded that there is a significant association of gastro-oesophageal reflux (GORD) and chronic rhinosinusitis (18). CRS subjects had greater prevalence of intranasal Helicobacter pylori and acid reflux than subjects without CRS. CRS is more prevalent in GORD sufferers than those without GORD. Also in this issue of the journal, the association between GORD and CRS is further objectified with 24-h multichannel intraluminal impedance (MII)-pH monitoring. The number of reflux episodes and proximal reflux episodes in the CRS patients was significantly higher than in the controls ${ }^{(18)}$.

An association is not the same as a causality and more studies are needed to show whether GORD is a cause, a contributing factor or the result of CRS.

When discussing the limitations of RCT's, everybody doing research knows that many patients we treat in daily practice do not fulfil the criteria of the trials we are performing. It is even worse, it is quite normal that less than 1 in 10 patients with a certain disease fulfils the criteria for a trial ${ }^{(19)}$. The reason behind such selective enrolment is to minimize the presence of confounding factors. However, the strict and controlled conditions in which RCT's are conducted, leads to low generalizability because they may be performed in conditions very different from real life usual care. Real life studies reflect how treatments/ interventions are administered in everyday clinical practice. They can consist of prospective or retrospective data collection but also consist of pragmatic trials where interventions are compared under routine clinical circumstances ${ }^{(20)}$.

Real-life studies to evaluate the "effectiveness" of a treatment, that is, the measure of the extent to which an intervention does what is intended to do in routine circumstances are rapidly expanding in respiratory research. Examples of recent studies in rhinitis and rhinosinusitis are ${ }^{(21-23)}$, but also earlier studies carefully and prospectively evaluating daily clinical practice can be included in this group ${ }^{(24-27)}$.

In 2015 president Obama launched the precision medicine initiative: "delivering the right treatment at the right time, every time, to the right person". Precision medicine is an emerging approach for disease treatment and prevention that takes into account individual variability in environment, lifestyle and genes for each person.

Last year we reported on the symposium in the European Parliament in Brussels that was organised by the ERS in collaboration with EAACl and the patient organisation EFA on Precision Medicine in Allergy and Airways Diseases ${ }^{(28)}$.

Precision Medicine represents a novel approach in medicine, embracing 4 key features: personalized care based on molecular, immunologic and functional endotyping of the disease, with participation of the patient in the decision-making process of therapeutic actions, and taking into account predictive and preventive aspects of the treatment. Within EUFOREA, the European Forum for Research and Education in Allergy and Airway disease (www.euforea.eu) we believe that the major scientific and economic challenges in airway diseases can be addressed through the promising possibilities of precision medicine. The use of precision medicine in allergies and airway diseases is still at its infancy, but it is our priority to make it a clinical reality. Also for precision medicine, we will need trials and evidence to understand how to use them. We will learn new terms like $\mathrm{N}$-of-1 trials (evaluating all data from one patient usually over a longer period of time) and basket trial: testing the effectiveness 
the effectiveness of an intervention on the basis of its mode of action, regardless of what disease it was designed to treat ${ }^{(28)}$. However, as the recently deceased Prof. Sackett already stated in 1996: "Evidence based medicine is the conscientious, explicit, and judicious use of current best evidence in making decisions about the care of individual patients" (29). I am convinced that that should and will remain the base of our daily clinical practice.

\section{References}

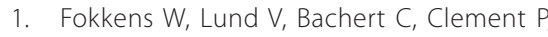
Helllings $P$, Holmstrom $M$, et al. European position paper on rhinosinusitis and nasal polyps. Rhinol Suppl. 2005(18):1-87.

2. Fokkens W, Lund V, Mullol J. EP3OS 2007 European position paper on rhinosinusitis and nasal polyps 2007. A summary for otorhinolaryngologists. Rhinology. 2007;45(2):97-101.

3. Fokkens WJ, Lund VJ, Mullol J, Bachert C Alobid I, Baroody F, et al. European Position Paper on Rhinosinusitis and Nasal Polyps 2012. Rhinol Suppl. 2012(23):3 p preceding table of contents, 1-298.

4. Rimmer J, Fokkens W, Chong LY, Hopkins C. Surgical versus medical interventions for chronic rhinosinusitis with nasal polyps. The Cochrane database of systematic reviews. 2014(12):Cd006991.

5. Chong LY, Head K, Hopkins C, Philpott C, Glew S, Scadding G, et al. Saline irrigation for chronic rhinosinusitis. The Cochrane database of systematic reviews. 2016:4:Cd011995.

6. Chong LY, Head K, Hopkins C, Philpott C, Schilder AG, Burton MJ. Intranasal steroids versus placebo or no intervention for chronic rhinosinusitis. The Cochrane database of systematic reviews. 2016:4:Cd011996.

7. Sng WJ, Wang DY. Efficacy and side effects of antibiotics in the treatment of acute rhinosinusitis: a systematic review. Rhinology. 2015;53(1):3-9.

8. Lal D, Jategaonkar AA, Borish L, Chambliss LR, Gnagi SH, Hwang PH, et al. Management of rhinosinusitis during pregnancy: systematic review and expert panel recommendations. Rhinology. 2016;54(2):99-104.

9. Musgrave KM, Powell J. A systematic review of anti-thrombotic therapy in epistaxis. Rhinology. 2016;54(4):292-391.

10. Pundir V, Pundir J, Georgalas C, Fokkens WJ. Role of tranexamic acid in endoscopic sinus surgery - a systematic review and metaanalysis. Rhinology. 2013;51(4):291-7.

11. Pundir V, Pundir J, Lancaster G, Baer S, Kirkland $\mathrm{P}$, Cornet M, et al. Role of corticosteroids in Functional Endoscopic Sinus Surgery--a systematic review and metaanalysis. Rhinology. 2016;54(1):3-19.

12. Sorokowska A, Drechsler E, Karwowski M, Hummel T. Effects of olfactory training: a meta-analysis. Rhinology. 2017.

13. Qiao H, Chen J, Li W, Shen X. Intranasa atomised dexmedetomidine optimises surgical field visualisation with decreased blood loss during endoscopic sinus surgery: a randomized study. Rhinology. 2016;54(1):38-44.

14. Konstantinidis I, Tsakiropoulou E, Constantinidis J. Long term effects of olfactory training in patients with post-infectious olfactory loss. Rhinology. 2016;54(2):170-5.

15. Schopf V, Kollndorfer K, Pollak M, Mueller CA, Freiherr J. Intranasal insulin influences the olfactory performance of patients with smell loss, dependent on the body mass index: A pilot study. Rhinology. 2015;53(4):371-8

16. Rawal RB, Deal AM, Ebert CS, Jr., Dhandha VH, Mitchell CA, Hang AX, et al. Postoperative budesonide irrigations for patients with polyposis: a blinded, randomized controlled trial. Rhinology 2015;53(3):227-34.

17. Cardesin A, Pontes C, Rosell R, Escamilla $Y$ Marco J, Escobar MJ, et al. A randomised double blind clinical trial to compare surgical field bleeding during endoscopic sinus surgery with clonidine-based or remifentanil-based hypotensive anaesthesia. Rhinology. 2015;53(2):107-15.

18. Katle EJ, Hatlebakk JG, Grimstad T, Kvaløy JT, Steinsvåg SK. Gastro-oesophageal re ux in patients with chronic rhino- sinusitis investigated with multichannel impedance - $\mathrm{pH}$ monitoring. Rhinology 2017; 55(1): 27-33.

19. Herland $K$, Akselsen JP, Skjonsberg $\mathrm{OH}$ Bjermer L. How representative are clinical study patients with asthma or COPD for a larger "real life" population of patients with obstructive lung disease? Respiratory medicine. 2005;99(1):11-9.

20. Saturni S, Bellini F, Braido F, Paggiaro P, Sanduzzi A, Scichilone N, et al. Randomized Controlled Trials and real life studies. Approaches and methodologies: a clinical point of view. Pulm Pharmacol Ther. 2014;27(2):129-38.

21. van der Veen J, Seys SF, Timmermans $M$, Levie P, Jorissen M, Fokkens WJ, et al. Reallife study showing uncontrolled rhinosinusitis after sinus surgery in a tertiary referral centre. Allergy. 2017;72(2):282-90.

22. Klimek L, Bachert C, Stjrne P, Dollner R, Larsen $\mathrm{P}$, Haahr $\mathrm{P}$, et al. MP-AzeFlu provides rapid and effective allergic rhinitis control in real life: A pan-European study. Allergy Asthma Proc. 2016;37(5):376-86

23. Droessaert $V$, Timmermans $M$, Dekimpe E, Seys S, Ceuppens JJ, Fokkens WJ, et al. Real-life study showing better control of allergic rhinitis by immunotherapy than regular pharmacotherapy. Rhinology. 2016;54(3):214-20.

24. Hopkins C, Rimmer J, Lund VJ. Does time to endoscopic sinus surgery impact outcomes in Chronic Rhinosinusitis? Prospective findings from the National Comparative Audit of Surgery for Nasal Polyposis and Chronic Rhinosinusitis. Rhinology. 2015;53(1):10-7.

25. Hopkins C, Andrews P, Holy CE. Does time to endoscopic sinus surgery impact outcomes in chronic rhinosinusitis? Retrospective analysis using the UK clinical practice research data. Rhinology. 2015;53(1):18-24.

26. Eccles R, Wilkinson JE. Exposure to cold and acute upper respiratory tract infection. Rhinology. 2015;53(2):99-106.

27. Bohman A, Oscarsson M, Holmberg K, Johansson L, Millqvist E, Nasic S, et al. Heredity of nasal polyps. Rhinology. 2015;53(1):25-8.

28. Muraro A, Fokkens WJ, Pietikainen S, Borrelli D, Agache I, Bousquet J, et al. European symposium on precision medicine in allergy and airways diseases: report of the European Union parliament symposium (October 14, 2015). Rhinology. 2015;53(4):303-7.

29. Schork NJ. Personalized medicine: Time for one-person trials. Nature. 2015;520(7549):609-11.

30. Sackett DL, Rosenberg WM, Gray JA, Haynes RB, Richardson WS. Evidence based medicine: what it is and what it isn't. BMJ (Clinical research ed). 1996;312(7023):71-2.

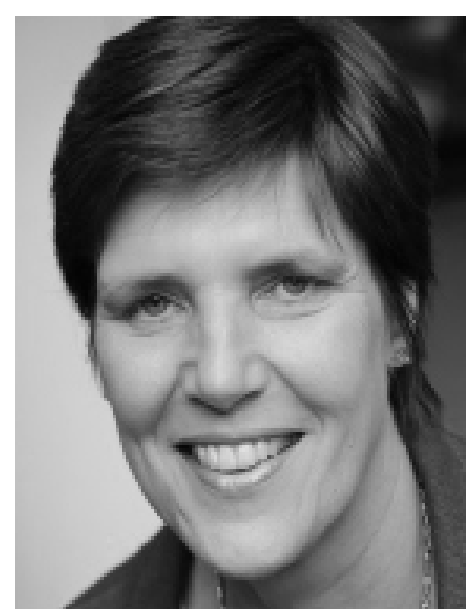

